\title{
TÉCNICAS MOLECULARES PARA LA IDENTIFICACIÓN Y TIPIFICACIÓN DEL VIRUS DEL PAPILOMA HUMANO
}

María del Pilar Correa Vásquez, Naydu Nope López, Jenny Rocio Rubiano Sechagua*

\section{Resumen}

La utilización de las técnicas de identificación molecular como las analizadas en el presente artículo (reacción en cadena de la polimerasa, técnica de captura de híbridos, southern dot y dot blot) permite clasificar y tipificar el virus del papiloma humano presente, para confirmar la asociación de algunas lesiones cervicales con tipos virales de alto y bajo grado, orientando de manera significativa un diagnóstico más acertado frente a otros métodos de detección o tamización rutinaria. Sin embargo, la implementación de dichas técnicas como método paraclínico de rutina, sería poco asequible para las pacientes por su elevado costo.

\section{Introducción}

El virus del papiloma humano (VPH) pertenece a la familia "Papovaviridae" y ya se han identificado cerca de 100 tipos. Posee un tropismo por la citoqueratina que contienen las células epiteliales escamosas, a donde llega para integrar su ADN viral al ADN de la célula huésped. La infección causada por el VPH puede permanecer de forma episomal o integrada. En forma episomal el ADN viral permanece en el citoplasma como una molécula libre, circular, lo que significa el mantenimiento de la infección sin producción del virus. En la forma integrada se produce la replicación del ADN viral conduciendo a la producción de viriones.

La información genética se encuentra contenida en una molécula de ADN circular de doble cadena con 8.000 pares de bases aproximadamente. Presenta una cápside icosaédrica (Figura 1), compuesta de 72 capsómeros con un diámetro de $55 \mathrm{~nm}$, conformados por dos proteínas estructurales L1 y L2 que rodean el genoma.

Estudiantes de VI Semestre, facultad de Citohistotecnología FUCS.

* Trabajo realizado bajo la tutoría de los docentes Dr. Darío Cadena Rey, Profesor de Patología, FUCS, Janeth León Enciso, Citohistotecnóloga FUCS Y Lilian Andrea Torres Tovar, Bacterióloga, Aspirante a Magister en Genética Humana, FUCS.
Los VPH poseen una homología aproximada del $90 \%$. Estos contienen entre siete y nueve genes, que se clasifican en (E) y (L). Los primeros (E1, E2, E4, E5, E6, E7) son de expresión temprana y están relacionados con el control de la replicación y la expresión de proteínas de transformación celular. E1 inicia la replicación y regula la trascripción del ADN viral. E2 es una proteína que funciona como reguladora en la transcripción de los genes E6 y E7. E4 se encuentra asociada con la ruptura de la citoqueratina en la célula. E5 interactúa con los receptores del factor de crecimiento celular para producir mitogénesis. E6 y E7 se encuentran asociadas a la transformación maligna. La expresión continua de E6 y E7 es necesaria para mantener el estado proliferativo en las células. Los genes de expresión tardía L1 y L2 codifican proteínas estructurales, su expresión ocurre en la fase final para la producción de viriones.

Los genomas de todos los tipos de VPH poseen un patrón de organización común, un filamento ADN que contiene dos marcos de lectura abiertos $\boldsymbol{O R F}$ "Open reading frames" o segmentos de codificación del gen, que codifican todas las proteínas virales. La ORF de la región temprana (E) codifica proteínas para la replicación viral y transformación celular. La región tardía (L) del genoma, contiene el ORF para L1 y L2 expresados en la fase de producción de nuevos virus. 


\section{Replicación viral}

Los genes L1 y E6 están separados por una región de ADN de 400 a 1000 pb, que varía dependiendo del tipo de VPH. Esta región no codifica ninguna proteína, pero contiene el origen "ori" secuencia de ADN donde se inicia la replicación viral.

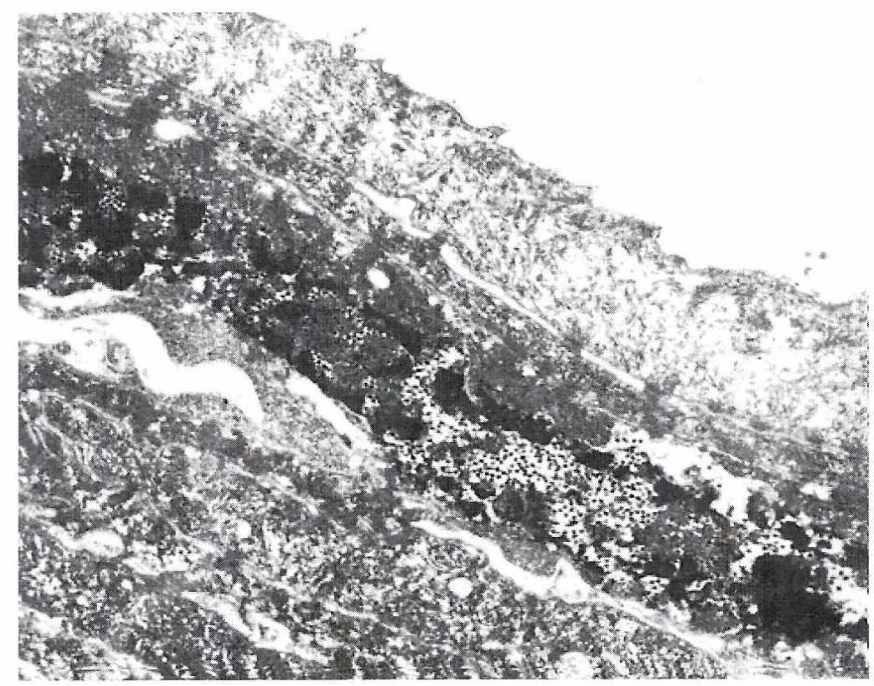

Fig. I. Microfotografía electrónica de transmisión. Se observan viriones del VPH en el epitelio cervical. (Cortesía del Dr. Gerzaín Rodríguez.ProfesorTitular y Maestro de la U.Nacional de Colombia; Investigador del Instituto Nacional de Salud. Bogotá, Colombia. 2004).

\section{Transcripción y síntesís de proteínas virales}

Los elementos que dirigen la expresión genética de estos virus se localizan en una región no codificadora, conocida como " $\mathrm{LRC}$ " región larga de control. La unión de estos sitios mediante varias proteínas celulares y virales, modula la transcripción viral y la replicación del ADN.

Al inicio del ciclo viral interactúan factores celulares con la LRC, promoviendo la transcripción temprana de los oncogenes virales E6 y E7 encargados de regular la replicación viral, los cuales favorecen la división célular interrumpiendo los mecanismos regulatoríos celulares. El gen E6 degrada la proteína supresora del tumor p53 y el gen E7 degrada la proteína p105 Rb+.

La transcripción temprana produce un aumento de las proteínas virales E1 y E2, esenciales para la replicación viral. La presencia de la proteína E2 impide la transcripción temprana de los genes E6 y E7 y permite la unión a la proteína $\mathrm{E} 1$, la cual promueve la replicación viral.

Es entonces cuando la ORF que corresponde a los genes L1 y L2 produce las proteínas de la cápside viral, permitiendo la maduración de viriones en el estrato superior del epitelio. La no producción de proteína E2 causada por la ruptura del gen E2 durante el evento de integración del genoma, impide la progresión del ciclo viral y baja la producción de viriones iniciando la transcripción de los genes E6 y E7.

\section{Clasificación y asociación entre VPH y lesiones cervicales}

Se han establecido más de 100 tipos de VPH; dentro de estos cerca de 40 se han asociado a lesiones del tracto genital. Los tipos 6, 11, 30, 34, 40, 42, 43, $44,53,55,57$ y 66 son denominados de bajo grado por estar presentes en condilomas y displasias leves. Los tipos 16, 18, 31, 33, 35, 39, 45, 51, 52, 54, 56 y 58 son considerados de alto grado, ya que han sido identificados en lesiones displásicas de alto grado "NIC II - III - Ca in situ" (Figura 2; Figura 3).

\section{Epidemiología}

Se estima que el cáncer cérvicovaginal causa alrededor de 500.000 muertes al año en el mundo. En Colombia donde la incidencia anual es de 23 por 1000.000, es una de las causas principales de mortalidad en las mujeres. En los países en desarrollo, su incidencia llega hasta 40 por 100.000 mujeres. En la actualidad el cáncer cervical afecta principalmente mujeres jóvenes, con una incidencia global de 400.000 casos nuevos diagnosticados cada año. Es de vital importancia continuar con la implementación de programas para la prevención del cáncer cervical.

\section{Técnicas de îdentificación molecular}

Las técnicas de identificación molecular permiten analizar las secuencias genómicas del ADN, 


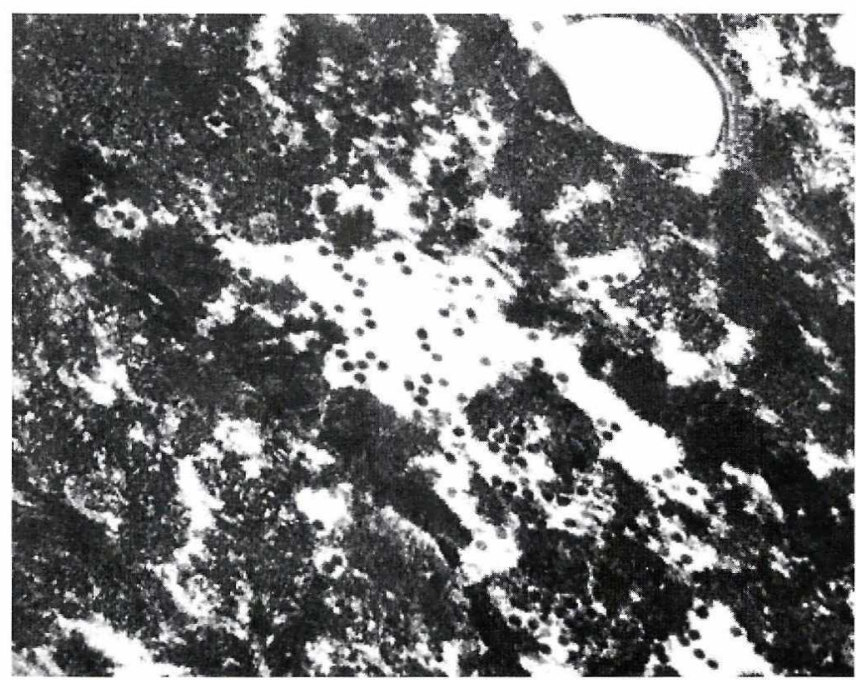

Fig. 2 Microfotografía electrónica de transmisión. Se observan viriones del VPH en el núcleo de una célula escamosa tipo intermedia, donde se ve vacuolización intranuclear. (Cortesía del Dr. Gerzaín Rodríguez. ProfesorTitular y Maestro de la U. Nacional de Colombia; Investigador del Instituto Nacional de Salud. Bogotá, Colombia. 2004).

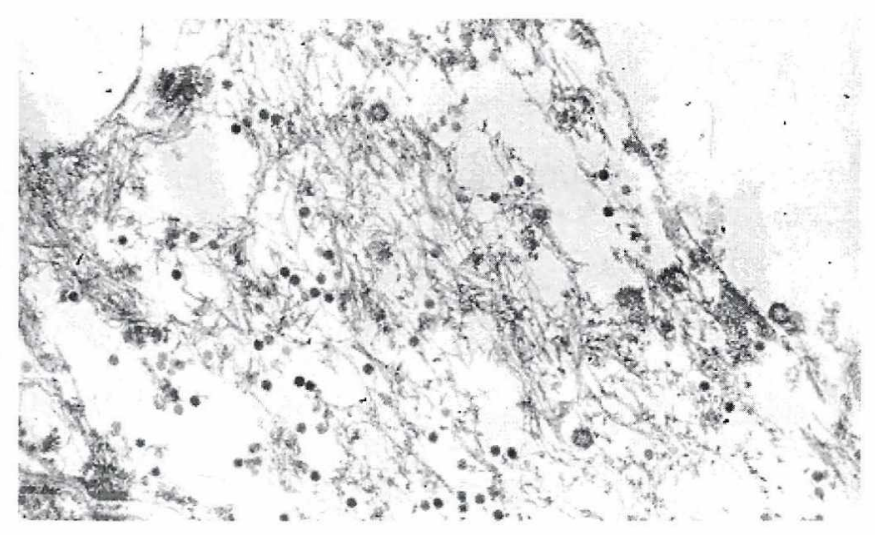

Fig. 3 Microfotografía electrónica de transmisión. En el citoplasma de una célula escamosa tipo superficial se evidencian prolongaciones acompañadas de queratinización y estructuras víricas del VPH, acompañadas de vacuolizaciones intracitoplasmáticas. (Cortesía del Dr. Gerzaín Rodríguez. Profesor Titular y Maestro de la U. Nacional de Colombia; Investigador del Instituto Nacional de Salud. Bogotá, Colombia. 2004).

logrando así grandes descubrimientos en el área de la medicina y en especial en la infección de los VPH en muestras citológicas y biopsias cervicovaginales.

Southern blot: denominada también transferencia de Southern, basada en la extracción del ADN de la muestra fresca o conservada. Permite identificar tipos y subtipos, e informar sobre el estado episomal o integrado en que se halla el $\mathrm{ADN}$ viral. Es una técnica que detecta fragmentos de $\mathrm{ADN}$, separados por tamaño mediante electroforesis en gel. Combina la separación electroforética del ADN con su transferencia a un soporte sólido o filtro de membrana para su hibridación.

Metodológicamente, implica cinco etapas: separación electroforética, desnaturalización, transferencia, hibridación y detección.

Dot blot: se utiliza para el estudio de ADN, directamente sobre una membrana de nitrocelulosa seguida de una hibridación con $\mathrm{ADN}$ marcado con fluoresceína. Esta técnica inmoviliza preparaciones de $\mathrm{ADN}$ en sonda por medio de un soporte sólido (una membrana de nylon). La hibridación con la muestra en blanco permite estudiar la cantidad de secuencias blanco estimadas por señales de intensidad. Este método detecta siete tipos de VPH: 6, 11, 16, 18, 31, 33, 35.

\section{Reacción en cadena de la polimerasa (PCR):} esta técnica consiste en crear copias adicionales de la secuencia deseada o segmento específico de ADN. Se realiza a través de ciclos repetidos de desnaturalización, hibridación y extensión.

La combinación apropiada de los primeros para PCR facilita la detección de VPH en lesiones intraepiteliales. Los primers más empleados en la identificación del virus son MY9-MY11 /GPS /Gp6, estos amplifican un amplio espectro de genotipos de VPH en muestras cervicovaginales y detectan similares tipos de VPH.

La detección de un tipo específico de ADN VPH es muy importante para la definición de la historia natural de la infección por VPH. Los primers MY9 - MY11 han sido usados predominantemente en estudios epidemiológicos originados en Norteamérica, Suramérica y Asia, mientras los GP5/GP6 son primers empleados en Europa.

De todas formas, debe buscarse el diagnóstico acertado empleando técnicas como PCR que permitan identificar y genotipificar con mayor acierto el tipo de infección viral. 


\section{Captura de híbridos: la "HCT técnica de captura} de hibridos" utiliza unas sondas de ARN específicas para diferentes tipos de VPH y empleando la hibridación busca blancos de ADN complementarios a la secuencia de ARN específica. Ha sido diseñada para detectar grupos virales, por lo que se puede aplicar para la búsqueda de grupos de virus de bajo o de alto riesgo.

Existen versiones mejoradas de la técnica de captura de híbridos tales como:

- Técnica de captura de híbridos I (HCT I)

- Técnica de captura de híbridos II (HCT II)

- Técnica de captura de y híbridos III (HCT III)

\section{Técnica de captura de híbridos (HCT 1) en tubos:} la muestra del paciente contiene ADN viral, esta se desnaturaliza y la cadena $\mathrm{ADN}$ sencilla se hibridiza en una solución mixta de ARN, que contiene 14 tipos virales; 5 de bajo riesgo $(6,11,42,43$ y 44$)$ y 9 de alto riesgo $(16,18,31,33,35,45,51,52,56)$.

\section{Técnica de captura de híbridos (HCT II) micro-} placa: en la captura de híbridos HCT II se utiliza una placa de microtítulo en cinta desprendible y cuatro sondas adicionales para tipos de VPH de alto riesgo. Puede detectar 13 diferentes tipos de VPH carcinógenos (tipos 16, 18, 31, 33, 35, 39, 45, 51, $52,56,58,59$ y 68 ) que representan virtualmente todos los tipos de VPH importantes que causan cáncer.

La HCT suministra suficiente ayuda diagnóstica para la rápida detección de VPH en muestras cervicales, esto permite la identificación de un amplio índice de tipos de VPH, logrando así la distinción de uno especifico de alto a bajo grado.

El uso en la clínica de esta técnica para la detección del VPH es útil para identificar pacientes con citologías que presenten cambios displásicos que impliquen riesgo de desarrollar un cáncer cervical. Algunos autores sugieren que la HCT puede ser usada en combinación con la citología cervicovaginal en la tamización o programas para la prevención del cáncer cervical, suministrando información más precisa acerca del estado del tracto genital femenino.

\section{Lecturas recomendadas}

Alonio V L, Dalbet, Picconi M A et al. Mutaciones en genes Ha-raS Y P 53 Detectadas mediante PCR - SSCP en Lesiones Premalignas y Malignas de Cuello Uterino Asociadas con Virus Papiloma Humano. Medicina de Buenos Aires 2000; 60: 895-901.

Canseco A L. Detección molecular del VPHs y otros virus genitales en muestras de tejido cervical. Chiapas: Universidad Antonio de Chiapas. 2000. Tesis para obtener el título de Químico Fármaco biólogo.

Clive C. Masure M. Bory JP et al. Hybrid Capture II based Huma Papillomavirus detection a sensitive test to detect toutine High - grade Cervical Lesions: A Preliminary study on 1518 women. Br J Cancer 1999; 80 (9):

Faro S D, Soper E. D. Enfermedades infecciosas en la mujer. México: Mc Grawn Hill; 2002 p 504-521.

Giannoudis A. Van Duin M, Snijders PJF et al. Variations in the E2-binding domain of HPV 16 are associated with high-grade sqamous intraepithelial lesions of the cervix. Br J Cancer 2001: 84 (8): 1058-1063.

Guerrero A, Avila C, Velasco P. Mejía Roberto F. ADN del HPV detectado en células escamosas atipicas de significado indeterminado ASCUS empleando la PCR: Reporte DE dos casos Act Cancer 2000; 30 (2).

Herrera H, Restrepo de Stiefken P. El virus del papiloma humano y su relación con la neoplasia cervical humana. Bogotá: Pontificia Universidad Javeriana, 2000.

Kuen W, Cheung K,N. Leslie, Li M S et al. Transitional Cell Metaplasia of the Uterine Cervix is Related to Human Papillomavirus: Molecular Analysis in Seven Patients with Cytohistologic Correlation. Can Cytop 2002; 96: 250-258.

Kulasingam L S, Hughes P J, Kiviat B N et al. Evaluation of Human Papillomavirus Testing in Primary Screening for Cervical Abnormalities: Comparison of Sensitivity, Specificity, and Frequency of Referral. JAMA 2002; 288 (14): 1749-57.

Liaw K, Hildesheim A, Burk D R et al. A Prospective Study of Human Papillomavirus (HPV) Type 16 DNA Detection by Polymerase Chain Reaction and its Association with Acquisition and Persistence of Other HPV Types. J Infect Dis 2001; 183: 8-15.

Luque J. Herraéz A. Texto ilustrado de biología molecular e ingeniería Genética, conceptos, técnicas y aplicaciones en ciencias de la salud. Madrid: Harcourt, 2001.

Matsura Y, Kawagoe T, Toki N, Sugihara K, Kashimura M. Low Grade Cervical intraepithelial Neoplasia Associated with Human Papillomavirus Infection. Act Cytol 1998; 42 (3): 625-630.

Molano M. Prevalence and determinants of HPV infection among Colombian women with normal cytology. Br J Cancer, 2002; 87: 324-333. 
